\section{Socio-cultural context and feelings of hatred and revenge in war veterans with post-trau- matic stress disorder 15 years after war in Kosovo}

\author{
Ramadan Halimi, 1 Emond Dragoti,2 \\ Hidajete Halimi, 3 \\ Nazife Sylejmani-Hulaj, 4 \\ Sevdie Jashari-Ramadani1 \\ 1Department of Psychiatry, Gjilan General \\ Hospital, Kosovo; 2Department of \\ Psychology, European University of \\ Tirana, Albania; ${ }^{3}$ Regional Centre of \\ Public Health, Gjilan, Kosovo; \\ 4Department of Psychiatry, University \\ Clinical Centre, UCC-Prishtina, Kosovo
}

\begin{abstract}
We aimed to assess, in socio-cultural context, the level of hatred and revenge in war veterans with post-traumatic stress disorder (PTSD). The sampling frame consisted of 215 Kosova War veterans, randomly selected. The Harvard Trauma Questionnaire was used to assess the prevalence of PTSD and Manchester Short Assessment of Life was used to assess social satisfactions. The participants were asked to declare the strength of feelings of hatred and revenge in the four preceding weeks by using four items scale: not at all, a little bit/sometimes, a lot and extremely. Willingness for action of veterans was distress 43.9\%. ${ }^{3}$ Also, Wenzel has emphasized an important fact that six years after the war, nearly $50 \%$ of civilian population confirmed experiencing a lot or extreme feelings of hatred. ${ }^{3}$ Feelings of revenge and a desire to act on them was expressed by $60.2 \%$, the frequency of fantasies of taking revenge (a lot or all the time) was reported to be at $24.7 \%$, and willingness to act on those feelings (affirmative and maybe response) was reported to be 17.4\%. Compared to Cordozo, ${ }^{4}$ Wenzel survey of 2006 reports a lower level of hatred and lower level of feelings of revenge and desires to act on them. In Cordozo survey, level of hatred has been reported at $60 \%$, while feelings of revenge and desire to act on them were reported at $43 \% .4$
\end{abstract} assessed using three item scale: yes, no or maybe. A probability level of 0.05 was adopted to be considered as statistically significant for differences among groups. DSM-IV-TR criteria for PTSD (very similar to DSM-V) were met by $52.6 \%$ of veterans; the data have confirmed existence of thoughts and fantasies of revenge against opposing forces by $42.8 \%$ veterans; at the same level $42.8 \%$ manifested feelings of hatred. Fantasies of taking revenge $a$ lot was recorded by $19.5 \%$ and extremely by $1.4 \%$ of veterans, while hateful thoughts at level $a$ lot were likely expressed by $22.3 \%$ and extreme by $2.8 \%$ of veterans. It is important to note that 84.7\% were confident to act based on their beliefs. Social-economic and cultural factors have played major role in the understanding of psychological problems of traumatized individuals with a direct impact on their ability to function socially. This study has confirmed the urgent need for the establishment of psychological rehabilitation programs as well as programs for the social and economic rehabilitation of War Veterans.

\section{Introduction}

During the war in Kosovo (January 1998 June 1999), over 18,000 people were killed, over 12,000 of them were civilians, and over 3900 were recorded as missing. The largest number of murders and massacres occurred in the period of March - June 1999. During this period, 25 to 35 in 10,000 inhabitants were killed and massacred. This scale of homicide was much higher than in other war fronts: e.g. in Cambodia, Thailand, Ethiopia or Sudan and Rwanda. More than in other wars, killings of civilians in Bosnia and Kosovo have caused severe trauma and a high prevalence of posttraumatic stress disorder (PTSD) and other anxiety disorders. 1,2

A survey in 2006 with the Kosovo civilian population identified a high prevalence of PTSD 22.6\%, associated with a high prevalence of Depressive Disorder 43.1\%, and emotional

The population census of 2011 in Kosovo has shown that about $45 \%$ of the active population is unemployed.5 Marshall (2005) in his study has emphasized that lower socioeconomic status can be associated with reduced resources of an individual to cope with trauma, which therefore could results in higher vulnerability to develop PTSD, and with low ability to cope with PTSD symptoms. ${ }^{6}$ Traumatic experience is likely influenced not only by the social context but also by the religious and cultural context in which it occurs. ${ }^{7}$ Odenwald findings that individuals with PTSD report higher levels of minor physical symptoms might indicate that the general poor physical health of traumatized individuals affects their ability to be productive members of society. ${ }^{8}$ From the cultural and social perspective, Kosovo Albanians are well known for their pride, patriotism, manhood, bravery, allegiance, loyalty, devotion to family, commitment to the preservation and appreciation of the moral values. ${ }^{9}$ The last decade is characterized by the tendency of a changing lifestyle, from a collective family, to individualistic organized life. The lack of abili-
Correspondence: Ramadan Halimi, Department of Psychiatry, Gjilan General Hospital, Murat Kryeziu No. 130, 60000 Gjilan, Kosovo.

E-mail: ramadan_halimi@yahoo.com

Key words: socio-cultural, hatred, revenge, posttraumatic stress disorder.

Contributions: the authors contributed equally.

Conflict of interests: the authors declare no potential conflict of interests.

Received for publication: 23 August 2014.

Revision received: 8 October 2014.

Accepted for publication: 10 October 2014.

This work is licensed under a Creative Commons Attribution NonCommercial 3.0 License (CC BYNC 3.0).

(C) Copyright R. Halimi et al., 2015

Licensee PAGEPress, Italy

Mental Illness 2015; 7:5609

doi:10.4081/mi.2015.5609

ty to adapt to the new conditions, on the part of the Kosovar Albanian population with traumatic experiences, has caused anxiety and tendency toward low self esteem. These changes were indeed one of the perpetuating factors of the high level of post traumatic stress disorder, depressive disorders, and other comorbid problems among Kosovo's population with traumatic experiences. In post-war Kosovo, because of the destruction of health facilities, health service capacities for all citizens, especially for those with mental health problems, have been very limited.10 In year 2002, under leadership of WHO, Kosovo mental health sector has been completely reformed. ${ }^{11}$ Even though every year mental health capacities in Kosovo are rising, they are still insufficient to cover all of the populations needs. The report of UNKT (2007) confirmed the following status of human resources in the mental health sector per 100,000 inhabitants: 1.89 Psychiatrist, 8.89 Nurses, 0.32 Clinical Psychologist and 0.52 Social workers. 12 In these circumstances exists a tendency towards overusing mental health services. ${ }^{13}$ However, on the other hand, as result of perceived stigma, and fears of humiliation in front of their colleagues and officers, veterans have avoided receiving mental health services. ${ }^{14}$ In the Balkans, PTSD of war veterans and symptomatology of fears' is still considered as weakness in a man and this is main reason of avoidance of mental health services. 15

The objective of our study was: assessment in socio-cultural context of level of hatred and revenge in war veterans with PTSD. 


\section{Materials and Methods}

The sampling frame consisted of 215 Kosova War Veterans, selected randomly from member lists of Kosova Veterans Association. The Harvard Trauma Questionnaire was used to assess the prevalence of PTSD (Cronbach's $\alpha=0.94$ ) and MANSA (Manchester Short Assessment of Life) was used to assess social satisfaction. ${ }^{16-18}$ Instruments were used in the CDC versions that had been validated either in the population or by translation-retranslation. ${ }^{4}$

The participants were asked to declare the strength of feelings of hatred and revenge in the four preceding weeks by using four items scale: not at all, a little bit/sometimes, a lot and extremely. Willingness for action of veterans was assessed using three item scale: yes, no or maybe.

Informed consent was obtained and confidentiality has been assured to all participants. The study was conducted following the approach of participatory research and by respecting ethical issues at all stages.

Data processing and analysis was carried out using SPSS 20 statistical package. A probability level of 0.05 was adopted a priori as the minimum level to be considered statistically significant for differences among groups. Associations between categorical variables were carried out using Chi-square. Measures of difference between variables were employed using t-test and Spearman's rho to test correlation between continuous variables.

\section{Results}

All the participants were males (100\%), with a mean age of $42.9 \pm 7.8$, range $35-65$ years; all subjects were divided into four age groups.
Veterans in age group 36-45 y/o were most represented with $47.4 \%$, followed by age group 46 55 with $24.7 \%$. The level of school education was as follows: $18.6 \%$ elementary school education, $48.4 \%$ high school education, $10.2 \%$ college education, and $14.9 \%$ high academic education. Results from all participants included, $42.8 \%$ unemployed, and $13 \%$ temporary employed, $85.6 \%$ were married, $63.7 \%$ unsatisfied with life achievements, $79.5 \%$ unsatisfied with the financial situation and $52.6 \%$ unsatisfied with living conditions.

After expert evaluation, DSM-IV-TR criteria for PTSD (very similar to DSM-V with regards to PTSD) were met by $52.6 \%$, criteria for PTSD in comorbidity with Major Depressive Disorder were met by $32.6 \%$, and criteria for Major Depressive Disorder were met by $35.8 \%$ of subjects.

The obtained data showed the existence of thoughts and fantasies of revenge against opponents resulted at $42.8 \%$ veterans; at the same level $42.8 \%$ manifested feelings of hatred. Fantasies of taking revenge $a$ lot was recorded in $19.5 \%$ and extremely in $1.4 \%$ of veterans, while hateful at level $a$ lot have expressed $22.3 \%$ and extreme $2.8 \%$ of veterans. It is important to note that $84.7 \%$ were confident to act based on their beliefs (Table 1).

The study shows that the level of hatred and desire for revenge is higher in veterans who had cases of murdered or missing family members during the war. Higher levels of hatred and desire for revenge also have shown up in veterans diagnosed with PTSD.

The study results have proven that the veterans who have had cases of murdered family members during the war, have expressed hatred $a$ lot in $14 \%$ of veterans, while the desire for revenge $a$ lot is expressed in $13 \%$ of veterans.

Veterans with missing family members have demonstrated lower rates of hatred, level of hatred $a$ lot has been expressed by $6.5 \%$, while the desire for revenge $a$ lot has been expressed in $5.1 \%$ of veterans.

The highest level of hate $a$ lot has been expressed by $16.7 \%$ of veterans diagnosed with PTSD, and the desire for revenge $a$ lot has been expressed in $14.9 \%$ of veterans with PTSD.

Veterans with PTSD have also shown the highest willingness for action based on their feelings: $43.7 \%$ (Table 2).

The study found a significant difference in the level of expression of hatred and desire for revenge among the group of veterans diagnosed with PTSD. Compared to others, veterans with murdered family members and with missing family members have been shown more predisposed towards hate and revenge. The obtained data indicate a medium negative correlation $(\mathrm{r}=-0.48)$ between the variables: feelings of hatred and murdered family members, and a medium negative correlation

Table 1. Hatred and revenge feelings in war veterans $(n=215)$ with post-traumatic stress disorder.

\begin{tabular}{lcc} 
Hatred and revenge feelings & N. & $\%$ \\
Fantasies of taking revenge & & \\
$\quad$ Not at all & 123 & 57.2 \\
Sometimes & 47 & 21.9 \\
A lot & 42 & 19.5 \\
$\quad$ All the time & 3 & 1.4 \\
Feelings of hatred & & \\
$\quad$ Not at all & 123 & 57.2 \\
A little bit & 38 & 17.7 \\
A lot & 48 & 22.3 \\
Extremely & 6 & 2.8 \\
\hline Willingness to act on this feelings & & \\
Yes & 182 & 84.7 \\
No & 14 & 6.5 \\
Maybe & 19 & 8.8 \\
\hline
\end{tabular}

Table 2. Hatred and revenge feelings in veterans with murdered family members, missing family members and post-traumatic stress disorder.

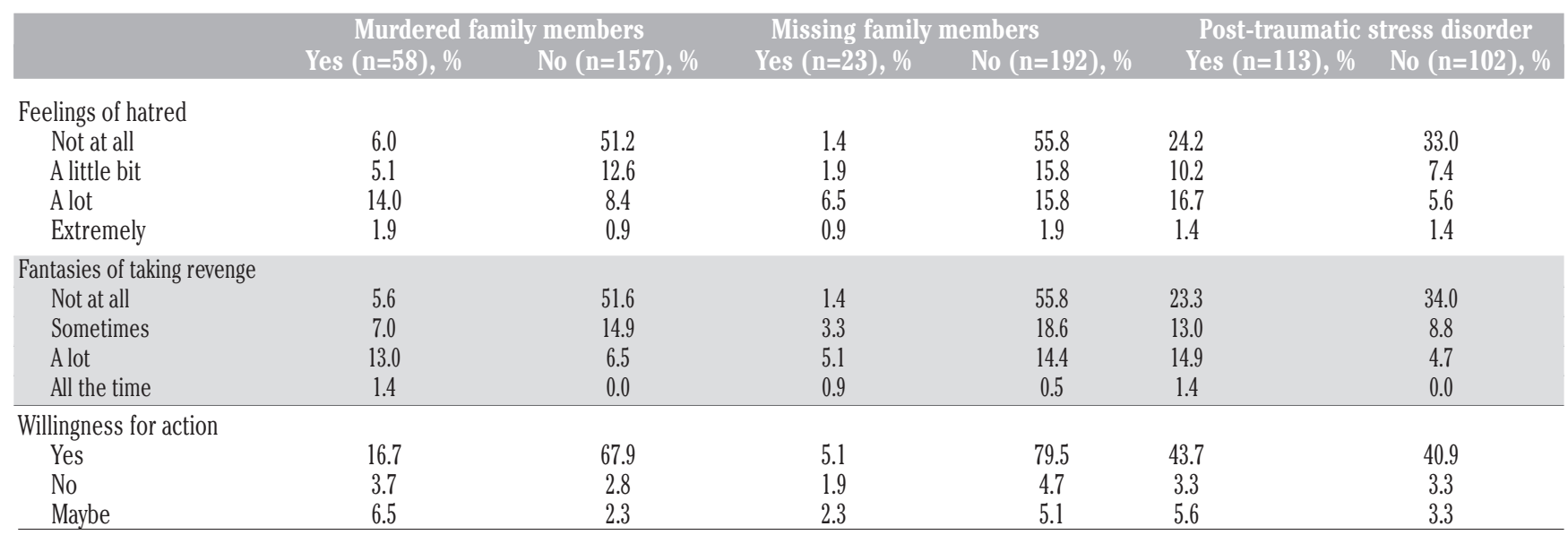


Table 3. Hatred and revenge feelings in veterans with murdered family members and missing family members.

\begin{tabular}{|c|c|c|c|c|c|c|c|c|c|c|}
\hline & \multicolumn{5}{|c|}{ Murdered family members ( $\mathrm{n}=58$ ) } & \multicolumn{5}{|c|}{ Missing family members ( $\mathrm{n=23}$ ) } \\
\hline & $\mathbf{r}$ & sig & $\mathrm{t}$ & df & $\operatorname{sig}(2 t)$ & $\mathbf{r}$ & sig & $\mathrm{t}$ & df & $\operatorname{sig}(2 t)$ \\
\hline Feelings of hatred & -0.48 & 0.000 & -0.28 & 214 & 0.77 & -0.36 & 0.000 & -2.57 & 214 & 0.010 \\
\hline Fantasies of taking revenge & -0.52 & 0.000 & -1.01 & 214 & 0.31 & -0.36 & 0.000 & -3.56 & 214 & 0.000 \\
\hline Post-traumatic stress disorder & -0.24 & 0.000 & 4.02 & 214 & 0.00 & -0.20 & 0.000 & 8.40 & 214 & 0.000 \\
\hline
\end{tabular}

( $\mathrm{r}=-0.52)$ between the variables: the desire for revenge and murdered family members.

Mild negative correlation $(\mathrm{r}=-0.36)$ was evidenced between variables: feelings of hatred and desire for revenge and missing family members (Table 3 ).

\section{Discussion}

Our study reveals several characteristic data: high prevalence of PTSD (52.6\%), very high unemployment (42.8\%), high dissatisfaction with life achievements (63.3\%), very high dissatisfaction with financial situation (79.5\%) and dissatisfaction of veterans with living conditions (52.6\%). Further, our study 15 years after the war in Kosovo reveals high levels of hatred (42.8\%), high levels of desires for revenge (42.8\%), and very high willingness to take action based on these feelings (84.7\%). The level of hatred and revenge still remain very high, even though presented data are lower than those of Wenzel survey of 2007.

High prevalence of PTSD (52.6\%) can be explained by the fact that Kosovo veterans have been witnesses of massive civilian departures and massive massacres against civilians. They participated in uneven guerrilla warfare, and often they were forced to fight for the protection of the civilian population and their families. 19

Furthermore, psychological problems of veterans with social problems and failure of economic achievements are usually more severe. As PTSD is often followed by or comorbid with other problems, it constitutes a significant risk factors in reintegration failure. ${ }^{8}$

Intolerance between ethnic groups in Kosovo has not changed significantly in the period between 1989-2003. People are grouped continuously within their ethnicity, and those groups were created long before the 1999 war. Also is believed that for a long time will be forwarded to the strong line of separation and there will be a few who will try to take action integration. ${ }^{20}$

PTSD, social problems, recent activities that remind them of traumatic experiences, such as the identification of human remains in massive graves in Serbia, and low ethnic toler- ance are some of the factors responsible for the current high levels of hatred and fantasies for revenge among Kosovo war veterans. Compared to previous studies, the prevalence of feelings of hatred and revenge in our study is considerably lower. Cordozo, ${ }^{4}$ a year after the war found significantly higher levels of hatred and revenge (89.5\%). Six years later, Wenzel has evidenced significant tendencies of lowering levels of feelings of hatred and revenge (50\%). ${ }^{3}$ In these tendencies, the pride and self satisfaction for given contribution to the freedom of the country, were seen as some of contributors. However, findings of our study show an important fact, the level of hatred and fantasies for revenge still remain very high and are specifically correlated with cases of veterans with murdered and missed family members during the war. We also found a specific correlation between PTSD and hatred and revenge. Besides clinical and social-economic factors, cultural factors have played a very important role in the acceptance of PTSD symptomatology. Culture influences the sources of distress, the form of the illness experienced, symptomatology, the interpretation of symptoms, modes of coping with distress, seeking help, and the social response to distress and disability. ${ }^{21}$ In Albanian culture, as in many other cultures, disturbances of mood, affect, and anxiety are not viewed only as mental health problems but also as social and moral norms. ${ }^{22}$ Many things (age, nationalization, acculturation, regionalization, peer influence, personal and family histories, personal experience, religion, personality) contribute to an individual's personal profile and reactions to experiences. ${ }^{23}$

\section{Conclusions}

In conclusion, social-economic and cultural factors have played major role in understanding of psychological problems of traumatized individuals with the direct impact on their ability to function socially. Lack of punishment for the aggressors and lack of justice for victims, among Kosovars is believed to have exacerbated social and psychological problems of persons with traumatic experiences, thus impeding the healing process. ${ }^{24}$

Finally, our study confirms the urgent need for the establishment of psychological rehabilitation programs as well as programs for the social and economic rehabilitation of War Veterans.

\section{References}

1. Spiegel P, Salama P. War and mortality in Kosovo, 1998-99; an epidemiological testimony; International Emergency and Refugee Health Branch (IERHB). Lancet 2000;355:2204-9.

2. Political Killings in Kosova/Kosovo, MarchJune 1999. A Cooperative report by Central and East European Law Initiative of the American Bar Association and the Science and Human Rights Program of the American Association for the Advancement of Science. Available from: https://hrdag.org/wp-content/uploads/ 2013/08/kosovo-politicalkillings-2000cc.pdf

3. Danish Refugee Council. Long-term sequels of war, social functioning and mental health in Kosovo. 2006. Available from: http://www.proasyl.de/fileadmin/ proasyl/fm_redakteure/Newsletter_Anhae nge/122/Longtime.pdf

4. Cordozo B, Vergara A, Agani F, Gotway C. Mental health, social functioning and attitudes of Kosovar Albanians following the war in Kosovo. JAMA 2000;284:569-77.

5. Kosovo Agency of Statistics. Kosovo population and housing census 2011. Final results. Available from: http://unstats. un.org/unsd/censuskb20/Attachment488.a spx

6. Marshall R, Olfson M, Hellman F, et al. Comorbidity, impairment, and suicidality in subthreshold PTSD. Am J Psychiatry 2001;158:1467-73.

7. Lanius R. Complex adaptations to traumatic stress: from neurobiological to social and cultural aspects. Am J Psychiatry 2007;164:11.

8. Odenwald M, Lingenfelder B, Schauer M, et al. Screening for posttraumatic stress disorder among somali ex-combatants: a 
validation study. Conflict and Health 2007;1:10.

9. Nushi P. Psikologjia e përgjithshme I. 2002. Available from: http://edukimi.unipr.edu/getattachment/Personeli/Personeliakademik/Xhafer-Ismajli/SyllabusiPSIKOLOGJI--E-PERGJITHSHME.pdf.aspx

10. Agani F. Mental health challenges in postwar Kosova. JAMA 2001;285:9.

11. De Vries A, Klazinga N. Mental health reform in post-conflict areas: a policy analysis based on experiences in Bosnia Herzegovina and Kosovo. Eur J Public Health 2006;16:246-51.

12. United Nations Kosovo Team. Initial observations on gaps in health care services in Kosovo. 2007. Available from: https://romarights.wordpress.com/2007/12/ 10/unkt-initial-observations-on-gaps-inhealth-care-services-in-kosovo-january2007/

13. National Center for PTSD. Health services use in department of veterans affairs among returning Iraq war and Afghan war veterans with PTSD. 2011. Available from http://www.ptsd.va.gov/professional/newsle tters/research-quarterly/v22n2.pdf

14. Hoge C, Castro C, Messer S, et al. Combat duty in Iraq and Afghanistan, mental health problems, and barriers to care. New Engl J Med 2004;351:13-22.

15. Boley CM. Caring and treating post-traumatic stress disorder in Bosnia and Herzegovina. 2007. Available from: http://digitalcollections.sit.edu/cgi/viewcontent.cgi?article=1228\&context=isp_co llection

16. Goldberg J, True W, Eisen S, Henderson W. A twin study of the effects of the Vietnam War on posttraumatic stress disorder. JAMA 1990;263:1227-32.

17. Allden K, Harvard Program in Refugee Trauma. Harvard Trauma Manual: BosniaHerzegovina version. Harvard: Harvard Program in Refugee Trauma; 1990.

18. Pribe S, Huxley P, Knight S, Evans S. The Manchester short assessment of quality of life (MANSA). Int $\mathbf{J}$ Soc Psychiatry 1999;45:7-12.

19. Wang SJ, Pacolli S, Rushiti F, et al. Survivors of war in the Northern Kosovo (II): baseline clinical and functional assessment and lasting effects on the health of a vulnerable population. Confl Health 2010;4:16.

20. Dyrstad K. After civil war: an empirical study of ethnic intolerance in the Western Balkans. Paper presented at the SGIR 7th Pan_European International Relations Conference, Stockholm; 9-11 September 2010.

21. Kitayama S, Markus H. Emotions and Culture: empirical studies of mutual influence. Washington DC; American Psychological Association; 1994.

22. Nader K. Treating people of varied cultures: honoring the individual context. 2007. Available from: http://www.giftfromwithin.org/pdf/culture.pdf

23. Wierzbicka A. Emotions across language and culture: diversity and universals. Cambridge: Cambridge University Press; 1999.

24. Basoglu M, Livanou M, Crnobaric C, et al. Psychiatric and cognitive effects of war in former Yugoslavia. Association of lack of redress for trauma and posttraumatic stress reactions. JAMA 2005;294:580-90. 